\title{
Aspectos ecológicos e epidemiológicos de acidentes ofídicos em comunidades ribeirinhas do baixo rio Purus, Amazonas, Brasil
}

\author{
Fabiano WALDEZ ${ }^{1,3}$, Richard C. VOGT²
}

\begin{abstract}
RESUMO
Acidentes ofídicos foram registrados em dez comunidades ribeirinhas do baixo rio Purus através de entrevista às vítimas. Os ribeirinhos responderam perguntas sobre a percepção ambiental da ecologia das serpentes envolvidas nos acidentes. O tamanho das serpentes e a altura da mordida no corpo foram estimados com fita métrica. A correspondência entre os nomes locais e científicos das serpentes foi levantada utilizando descriçôes e imagens das espécies. Para outras 17 comunidades dados adicionais do número de famílias com vítimas de acidentes ofídicos foram avaliados através do diagnóstico sócio-ambiental da Reserva de Desenvolvimento Sustentável Piagaçu-Purus. Foram entrevistados 18 ribeirinhos e registrados 28 acidentes ofídicos em cinco comunidades. O número de vítimas por comunidade não teve relação com o tamanho da população. O número de famílias com vítimas foi maior em comunidades maiores $\left(\mathrm{r}^{2}=0,444 ; \mathrm{p}=0,003\right)$. Aproximadamente $88 \%$ das mordidas foram nos membros inferiores. Não houve relação do tamanho estimado da serpente com a altura da mordida. A maioria dos acidentes ocorreu de dia $(82,14 \%)$ e no período de cheia $(64,28 \%)$ na época de exploração da castanha-da-Amazônia e da madeira pelos ribeirinhos, atividades que despendem maior tempo na floresta. Um único caso de morte por acidente ofídico foi registrado. A serpente Bothrops atrox foi à espécie mais relacionada com acidentes na região. O reconhecimento das serpentes pelos ribeirinhos revelou várias sinonímias, com 20 nomes locais atribuídos a 33 espécies. Na percepção dos ribeirinhos as serpentes $B$. atrox e Lachesis muta foram às espécies mais temidas e diferem no comportamento de ataque.
\end{abstract}

PALAVRAS-CHAVES: Serpentes, ofidismo, percepção ambiental, rio Purus, Amazônia.

\section{Ecological and epidemiological aspects of snakebites in riverside communities of the lower Purus River, Amazonas, Brazil.}

\section{ABSTRACT}

Snakebites were registered in 10 riverside communities of the lower Purus River through interviews with the victims. Local inhabitants answered questions about their perception on ecological aspects of snakes species involved in snakebites. Snake size and bite height on the victim body were estimated with measuring tape. Correspondence of local names and scientific species were obtained by using descriptions and images of the snakes. Additional data on the number of families with snakebites victims were obtained from social-economic surveys for other 17 communities in the Piagaçu Purus Reserve. Eighteen people and 28 snakebites events were registered in five communities. The number of victims per community was not related to population's size. The number of families with victims was higher in larger communities $\left(\mathrm{r}^{2}=0.444 ; \mathrm{p}=0.003\right)$. Approximately $88 \%$ of snakebites were inflicted on the lower limbs of the victims. There was no relationship between estimated snake's size and the height of the bite. Most snakebites occurred at daytime (82.14\%), and during the high rive period (64.28\%) that coincides with the extraction of brazil nut and timber by the local people when they spend more time in the forest. Only one death due to snakebite was registered. The species Bothrops atrox was responsible for most of the accidents in the region. Snake's identification by local people revealed various synonymies, with 20 local names attributed to 33 species. In their perception, B. atrox and Lachesis muta were the most dangerous species and differ in attack behavior.

KEY WORDS: Serpentes, snakebite, environmental perception, Purus River, Amazon.

\footnotetext{
1 Instituto Piagaçu. Morada do Sol, Rua UZ, Quadra Z, n’08. Aleixo. Manaus, Amazonas.69060-095. E-mail: fwaldez@yahoo.com.br

2 Instituto Nacional de Pesquisas da Amazônia. E-mail: vogt@inpa.gov.br

${ }^{3}$ Pós-Graduação em Ecologia, INPA
} 


\section{INTRODUÇÃO}

As serpentes correspondem ao grupo de répteis Squamata com maior riqueza em florestas Neotropicais variando entre cerca de 50 até 130 espécies por região (Dixon \& Soini, 1986; Duellman, 1990; Doan \& Arizábal 2002; Savage, 2002). Nestes ambientes, esses répteis predadores participam de complexas teias alimentares que envolvem uma grande heterogeneidade de invertebrados e vertebrados (Strüssmann \& Sazima, 1993; Martins \& Oliveira, 1998; Bernarde \& Abe 2006).

Por sua natureza caçadora algumas espécies de serpentes podem adotar posturas defensivas agressivas (ver Martins, 1996) que, em geral, induzem nas pessoas atitudes extremas de extermínio das serpentes, contribuindo para este grupo ter sido historicamente estigmatizado como "animais nocivos" (Greene, 1997).

Ações educativas que promovam o conhecimento sobre as serpentes e as relações destas com o ambiente têm sido apontadas como uma eficiente estratégia para atribuir valor de conservação ao grupo (Dodd, 1993). Isto, porque de uma maneira geral, os prejuízos ocasionados pela extinção local de serpentes são pouco divulgados como, por exemplo, a erosão da variabilidade genética das populações com conseqüente perda de substâncias de potencial fármaco-químico presentes na peçonha das espécies (Ferreira, 1994; Da Silva et al., 1996; Furtado, 2007). Também, as flutuaçōes das populaçōes de suas presas (e.g. roedores) e de parasitos relacionados com estas (e.g. artrópodes vetores de agentes etiológicos).

Apenas $14 \%$ do total de aproximadamente 3.000 espécies de serpentes conhecidas utilizam a tática de subjugar as presas por envenenamento como principal estratégia alimentar (Barraviera \& Pereira, 1994). Serpentes peçonhentas perigosas aos humanos também se encontram ausentes de várias regiōes do planeta como Chile, Hawaii e outras ilhas do Pacífico; da maioria das ilhas do oeste do Mediterrâneo, do Atlântico e do Caribe, e de ilhas maiores como Irlanda, Madagascar, Nova Caledônia e Nova Zelândia (Warrell, 2003; Campbell \& Lamar, 2004). Além disso, serpentes peçonhentas são consideradas de pouca importância para a saúde pública em grande parte da área onde ocorrem como, por exemplo, na Canadá, Europa e Japão (Chippaux, 1998).

Chippaux (1998) estimou que anualmente ocorreriam 2.500.000 acidentes ofídicos no mundo, resultando na morte de aproximadamente 125.000 pessoas. A maior parte destes acidentes distribuídos na zona tropical e subtropical (Warrell, 1992; Gutiérrez et al., 2006), onde há uma grande diversidade de serpentes convivendo com uma população humana campesina de acesso limitado à tecnologia rural.

$\mathrm{Na}$ América Latina, acidentes com serpentes constituem um relevante problema de saúde pública, ocasionando altas taxas de morbidade e mortalidade (Fan \& Cardoso, 1995; Gutiérrez, 1995; Warrell, 2004). As principais serpentes de interesse médico nas Américas são da família Viperidae, subfamília Crotalinae (cascavéis, jararacas e surucucus) (Fan \& Cardoso, 1995; Gutiérrez, 1995; Warrell, 2004), que possuem dentição solenóglifa, com dentes anteriores maiores e móveis, altamente especializados para a injeção de peçonha (Campbell \& Lamar, 2004).

As jararacas se destacam como o grupo mais diversificado com os gêneros Atropoides, Bothriechis, Bothriopsis, Bothrocophias, Bothrops, Cerrophidion, Ophryacus e Porthidium (Campbell \& Lamar, 2004), relacionados a uma alta incidência de acidentes, maior que a dos acidentes com cascavéis (Crotalus spp. e Sistrurus spp.) e com surucucus (Lachesis spp.), apesar de estes dois últimos grupos causarem acidentes de maior letalidade que as jararacas (Fan \& Cardoso, 1995; Gutiérrez, 1995; Araújo et al., 2003; Praba-Egge et al., 2003; Gutiérrez et al., 2006).

Nas mesmas regióes, ocorrem outros grupos de importância médica relativamente menor como as serpentes da família Elapidae, sub-família Elapinae (corais verdadeiras), representada pelos gêneros Leptomicrurus e Micrurus, de dentição proteróglifa, com dentes anteriores maiores, fixos e especializados na injeção da peçonha (Roze, 1996). Também, algumas serpentes da família Colubridae, subfamília Xenodontinae, capazes de envenenamento humano e representadas pelos gêneros Boiruna, Clelia, Erythrolamprus, Leptodeira, Oxyrhopus, Phalotris, Philodryas, Tachymenis e Thamnodynastes, de dentição opistóglifa, com dentes posteriores maiores e imóveis, especializados na injeção de peçonha (Gutiérrez \& Sasa, 2002; Prado-Franceschi \& Hyslop, 2002; Savage, 2002; Puorto \& França, 2003; Salomão et al., 2003; Serapicos \& Merusse, 2006).

Ainda, espécies de serpentes com dentição áglifa, com dentes indiferenciados e não especializados na injeção de peçonha, mas capazes de causar ferimentos com alto risco de infecção da família Boidae, sub-família Boinae, como Boa constrictor e espécies dos gêneros Corallus, Epicrates e Eunectes (jibóias, suaçubóias, salamantas e sucuris) (Jorge \& Ribeiro, 1991; Puorto \& França, 2003). Também, espécies da família Colubridae (Xenodontinae), como os gêneros Helicops e Liophis que possuem na saliva enzimas e peptídeos de ação anti-coagulante e alergênica (Prado-Franceschi \& Hyslop, 2002; Puorto \& França, 2003).

Apesar da importância dos acidentes ofídicos para a saúde pública de vários paises latino-americanos, aspectos relacionados à pesquisa epidemiológica, ao acesso ao tratamento e à qualificação de profissionais em saúde ainda são negligenciados pelas políticas públicas nacionais (Gutiérrez et al., 2006; 2007). No Brasil, por exemplo, mais de 20.000 acidentes são registrados anualmente, com uma mortalidade 
associada de $0,45 \%$ (cerca de 90 pessoas/ano), com maior frequiência na zona rural (SINITOX, 2007), e mais de $90 \%$ dos eventos provocados por espécies do gênero Bothrops (Ministério da Saúde, 2001; Araújo et al., 2003; Bochner \& Struchiner, 2003). Estas estimativas, entretanto, encontram-se subestimadas pelas dificuldades de registro dos acidentes nas regiōes mais remotas do país, em especial no Centro-Oeste, Nordeste e Norte do país (Ministério da Saúde, 2001).

$\mathrm{Na}$ região Norte do Brasil ocorre a segunda maior incidência de acidentes ofídicos do país (24/100.000 habitantes), menor apenas que na região Centro-Oeste (33/100.000 habitantes) (Ministério da Saúde, 2001; Pinho \& Pereira, 2001). Entretanto, na Amazônia brasileira ainda são poucos os estudos sobre acidentes ofídicos (Pardal et al., 1995; Sá-Neto \& Santos, 1995; Dos-Santos et al., 1995; Carvalho \& Nogueira, 1998; Borges et al., 1999; Nascimento, 2000; Oliveira \& Martins, 2001).

No Amazonas, o maior dos estados brasileiros, a mortalidade de $1 \%$ associada aos acidentes ofídicos é mais alta (Dos-Santos et al., 1995; Borges et al., 1999) que a média nacional de 0,4\% (Ministério da Saúde, 2001; Araújo et al., 2003; Bochner \& Struchiner, 2003) e o problema da subnotificação é agravado porque grandes distâncias são percorridas apenas por via fluvial, havendo diversas localidades com um perfil epidemiológico pouco ou nada conhecido (ver Borges et al., 1999). Neste trabalho, registramos aspectos ecológicos e epidemiológicos de acidentes ofídicos em comunidades ribeirinhas do Amazonas, na Amazônia central.

\section{MATERIAIS E MÉTODOS}

\section{ÁREA DE ESTUDO}

$\mathrm{O}$ estudo foi realizado entre os meses de maio e junho de 2005, em 10 comunidades ribeirinhas do Lago Ayapuá, localizado no baixo curso do rio Purus, na Reserva Estadual de Desenvolvimento Sustentável Piagaçu-Purus (RDS-PP), município de Beruri, estado do Amazonas, Brasil. (Figura 1).

Nesta região, a pluviosidade média é de 2600/ano com distribuição sazonal das chuvas, sendo maior a concentração entre os meses de fevereiro e junho, e menor a pluviosidade entre os meses de julho e outubro (Haugaasen $\&$ Peres, 2006). O nível fluvial do rio Purus na região pode variar cerca de 12 m entre os maiores níveis de enchente e os menores níveis de vazante, e a paisagem local é composta por um mosaico de vegetaçōes florestais de terra-firme e de florestas sazonalmente alagáveis de várzea e igapó (Haugaasen \& Peres, 2006).

O lago Ayapuá está localizado a cerca de $120 \mathrm{~km}$, por via fluvial, da sede do município de Beruri. Durante o período de cheia, o espelho d'água do lago pode alcançar mais de 20 $\mathrm{km}$ entre as margens. Dez comunidades ribeirinhas de origem não-indígena e três comunidades de origem indígena ocupam a região do lago, desde a "boca do lago", próxima do canal do rio Purus, até o "paraná grande do lago", onde estão as cabeceiras de vários igarapés (Figura 1).

\section{COLETA DE DADOS}

Foram visitadas as dez comunidades não-indígenas do lago: Bom Jesus, Boa Esperança (Evaristo), Divino Espírito Santo (Pinheiros), São Sebastião (Craviana) e Nossa Sra. do Livramento (Uixí). A maioria destas comunidades está localizada em áreas de floresta de terra-firme, com exceção da comunidade de Bom Jesus localizada em área de floresta de várzea (Figura 1).

Informaçôes sobre os acidentes ofídicos, as circunstâncias associadas e os aspectos bioecológicos das serpentes, foram levantadas através da aplicação de questionário aos ribeirinhos vitimados. Nos casos de crianças acidentadas ou de óbito, o questionário foi aplicado ao adulto que presenciou o evento ou prestou assistência à vítima.

Para estimar o tamanho da serpente envolvida no acidente e a altura da mordida no corpo da vítima em relação ao solo, os entrevistados utilizaram uma fita métrica flexível de $10.000 \mathrm{~mm}$. Para comparar o tamanho estimado da serpente e a altura da mordida no corpo da vítima os dados métricos foram transformados em logaritmo de base 10 e a relação foi avaliada por regressão linear.

A relação entre o número de pessoas acidentadas registradas neste estudo e o número de habitantes de suas comunidades foi verificada por regressão linear.

Também foram analisados dados adicionais sobre ocorrência de acidentes com serpentes para outras 17 comunidades ribeirinhas da região, através do diagnóstico sócio-ambiental da RDS-PP realizado em 2005 pelo Instituto Piagaçu (IPi) organização não-governamental que atua como co-gestor da RDS-PP em acordo com o Centro Estadual de Unidades de Conservação do Amazonas (CEUC/SDS). Este diagnóstico levantou em cada comunidade o número de famílias com vítimas de acidentes ofídicos, expresso como número de residências com vítimas. Este número foi relacionado com a população destas comunidades através de regressão linear.

Todas as análises e testes estatísticos foram feitos utilizando o programa SYSTAT 8.0 (Wilkinson, 1990).

Os moradores vitimados foram inquiridos sobre os nomes locais utilizados para reconhecimento das espécies de serpentes para estabelecer correspondência com a nomenclatura científica das serpentes. Para tanto, utilizamos descriçóes e fotos de serpentes amazônicas do livro Bartlett \& Bartlett (2003) e do artigo Martins e Oliveira (1998), tomando como base um inventário da herpetofauna feito na região da RDS-PP (Waldez et al., 2006). A nomenclatura taxonômica utilizada 


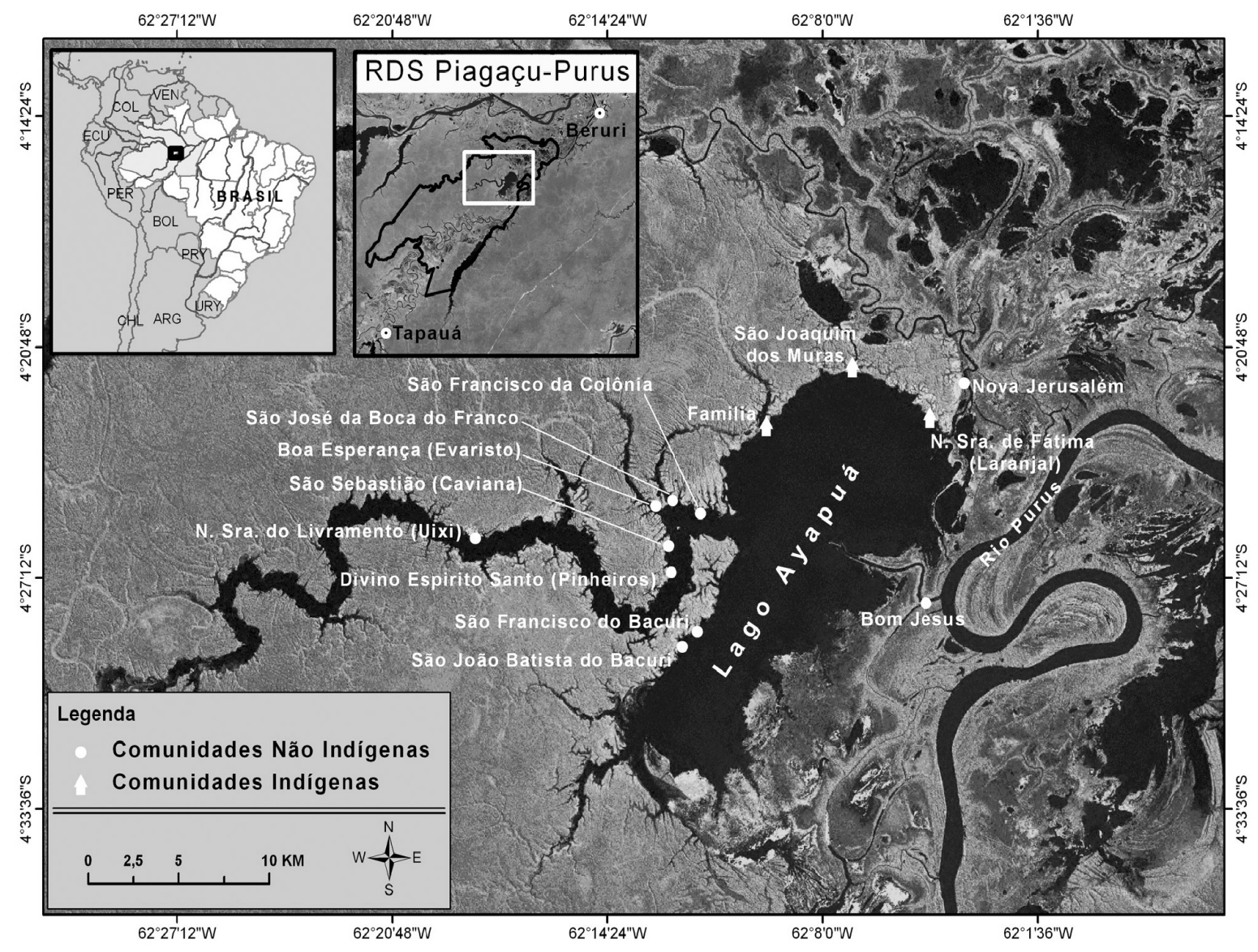

Figura 1 - Localização do Lago Ayapuá na Reserva de Desenvolvimento Sustentável Piagaçu-Purus, bacia do baixo rio Purus, e das dez comunidades ribeirinhas não indígenas estudadas.

foi a da lista de espécies de répteis do Brasil da Sociedade Brasileira de Herpetologia (SBH, 2008).

As serpentes reconhecidas pelos moradores da região também foram classificadas quanto ao risco de acidentes ofídicos com base no comportamento de defesa e no tipo de dentição, evidenciados através da literatura especializada (Martins e Oliveira, 1998; Bartlett \& Bartlett 2003), e por nossas observações durante trabalhos de campo com as espécies na região. Com relação ao potencial de acidentes, as espécies foram alocadas em três diferentes categorias: a) perigosa - espécies com dentição proteróglifa ou solenóglifa; b) agressiva - espécies com dentição áglifa ou opistóglifa, que utilizam a mordida como defesa e c) pacífica - espécies com dentição áglifa ou opistóglifa, que não utilizam a mordida como defesa.

Os ribeirinhos entrevistados também responderam perguntas relacionadas à percepção ambiental sobre quais seriam as espécies de serpentes mais envolvidas com acidentes na região, o comportamento e ecologia destas espécies e o período do ano em que os acidentes ofídicos são mais freqüentes na região.

\section{RESULTADOS}

\section{ASPECTOS EPIDEMIOLÓGICOS}

Em cinco das dez comunidades pesquisadas foram encontradas pessoas vitimadas por serpentes. Nestas, foram entrevistados 18 ribeirinhos e obtidos registros de 28 eventos envolvendo acidentes ofídicos, com uma média de 1,67 (DP= $\pm 0,84$ ) acidentes por entrevistado e um máximo de quatro acidentes sofridos por uma mesma vítima. Dois questionários foram aplicados a terceiros, um para a mãe de uma criança vitimada e outro para o filho de um homem que faleceu em decorrência do acidente.

O número de acidentes registrados por comunidade variou de um a 12 (Tabela 1). Estes registros compreenderam eventos ocorridos em prazos de menos de um ano até 50 anos e a maioria dos envolvidos foram homens (82,14\%) (Tabela 2). 
Tabela 1 - Características sócio-econômicas de cinco comunidades ribeirinhas onde foram entrevistadas vítimas de acidentes ofídicos, no Lago Ayapuá na Reserva de Desenvolvimento Sustentável Piagaçu-Purus, região do baixo rio Purus, (Fonte: Instituto Piagaçu).

\begin{tabular}{|c|c|c|c|c|c|c|}
\hline Comunidade & Localização & Habitantes & $\begin{array}{l}\text { Casas na terra- } \\
\text { firme }\end{array}$ & Casas flutuantes & Principais atividades econômicas & Acidentes \\
\hline Bom Jesus & $\begin{array}{l}62^{\circ} 4^{\prime} 56^{\prime \prime} W \\
4^{0} 27^{\prime} 55^{\prime \prime} S\end{array}$ & 57 & 0 & 6 & Agricultura, pesca e caça. & 1 \\
\hline $\begin{array}{l}\text { Boa Esperança } \\
\text { (Evaristo) }\end{array}$ & $\begin{array}{l}62^{0} 12^{\prime} 49^{\prime \prime} W \\
4^{0} 25^{\prime} 28^{\prime \prime} S\end{array}$ & 35 & 6 & 3 & $\begin{array}{l}\text { Agricultura, pesca e coleta de } \\
\text { castanha da Amazônia }\end{array}$ & 4 \\
\hline $\begin{array}{l}\text { Divino Espíto Santo } \\
\text { (Pinheiros) }\end{array}$ & $\begin{array}{l}62^{0} 12^{\prime} 27^{\prime \prime} W \\
4^{0} 27^{\prime} 0,9^{\prime \prime} S\end{array}$ & 128 & 20 & 4 & $\begin{array}{l}\text { Agricultura, pesca, caça e coleta } \\
\text { de castanha da Amazônia }\end{array}$ & 12 \\
\hline $\begin{array}{l}\text { São Sebastião } \\
\text { (Craviana) }\end{array}$ & $\begin{array}{l}62^{0} 12^{\prime} 36^{\prime \prime} W \\
4^{0} 26^{\prime} 18^{\prime \prime} S\end{array}$ & 38 & 5 & 0 & $\begin{array}{l}\text { Agricultura, pesca e coleta de } \\
\text { castanha da Amazônia }\end{array}$ & 8 \\
\hline $\begin{array}{l}\text { Nossa Sra. do } \\
\text { Livramento (Uixí) }\end{array}$ & $\begin{array}{l}62^{\circ} 18^{\prime} 9^{\prime \prime W} \\
4^{0} 26^{\prime} 09^{\prime \prime S}\end{array}$ & 184 & 28 & 3 & $\begin{array}{l}\text { Agricultura, pesca, caça e coleta } \\
\text { de castanha da Amazônia }\end{array}$ & 3 \\
\hline
\end{tabular}

Tabela 2 - Quantidade de acidentes ofídicos segundo o tempo decorrido do acidente e o sexo das vítimas em cinco comunidades ribeirinhas no Lago Ayapuá na Reserva de Desenvolvimento Sustentável Piagaçu-Purus, região do Baixo Purus.

\begin{tabular}{|c|c|c|c|c|c|c|}
\hline \multirow{3}{*}{ Anos decorridos } & \multicolumn{6}{|c|}{ Sexo } \\
\hline & \multicolumn{2}{|c|}{ Masculino } & \multicolumn{2}{|c|}{ Feminino } & \multicolumn{2}{|c|}{ Total } \\
\hline & $n$ & $\%$ & $\mathrm{n}$ & $\%$ & $\mathrm{n}$ & $\%$ \\
\hline $0-1$ & 3 & 13,06 & 0 & 0 & 3 & 10,71 \\
\hline$>1-4$ & 2 & 8,69 & 1 & 20 & 3 & 10,71 \\
\hline$>4-8$ & 0 & 0 & 1 & 20 & 1 & 3,57 \\
\hline$>8-16$ & 2 & 8,69 & 3 & 60 & 5 & 17,85 \\
\hline$>16-25$ & 8 & 34,79 & 0 & 0 & 8 & 28,58 \\
\hline$>25-33$ & 2 & 8,69 & 0 & 0 & 2 & 7,14 \\
\hline$>33-40$ & 2 & 8,69 & 0 & 0 & 2 & 7,14 \\
\hline \multirow[t]{2}{*}{$>40-50$} & 4 & 17,39 & 0 & 0 & 4 & 14,30 \\
\hline & 23 & 100 & 5 & 100 & 28 & 100 \\
\hline
\end{tabular}

Das 17 comunidades avaliadas pelo diagnóstico sócioambiental da RDS-PP, dez comunidades tiveram famílias com incidência de acidentes ofídicos, com uma média de 2,47 $(\mathrm{DP}= \pm 3,12)$ famílias acidentadas/comunidade, e um máximo de dez famílias por comunidade.

Não houve relação significativa entre o número de acidentes e o de habitantes nas cinco comunidades onde as vítimas foram entrevistadas $\left(\mathrm{r}^{2}=0,010 ; \mathrm{p}=0,874\right)$. No entanto, nas 17 comunidades onde foi realizado censo sócioeconômico, o número de residências com casos de acidentes ofídicos foi positivamente relacionado com o tamanho da população $\left(r^{2}=0,444 ; p=0,003\right.$; Figura 2$)$.

Nos 28 eventos avaliados através de entrevista, aproximadamente $88 \%$ das mordidas ocorreram nos membros inferiores das vítimas (Tabela 3). Mais de $80 \%$ dos entrevistados relataram estarem descalços no momento do acidente e 39,29\% alegaram ter tocado ou pisado na serpente.

Em 26 casos foi possível medir a altura da mordida no corpo da vítima em relação ao solo. Foi encontrada altura

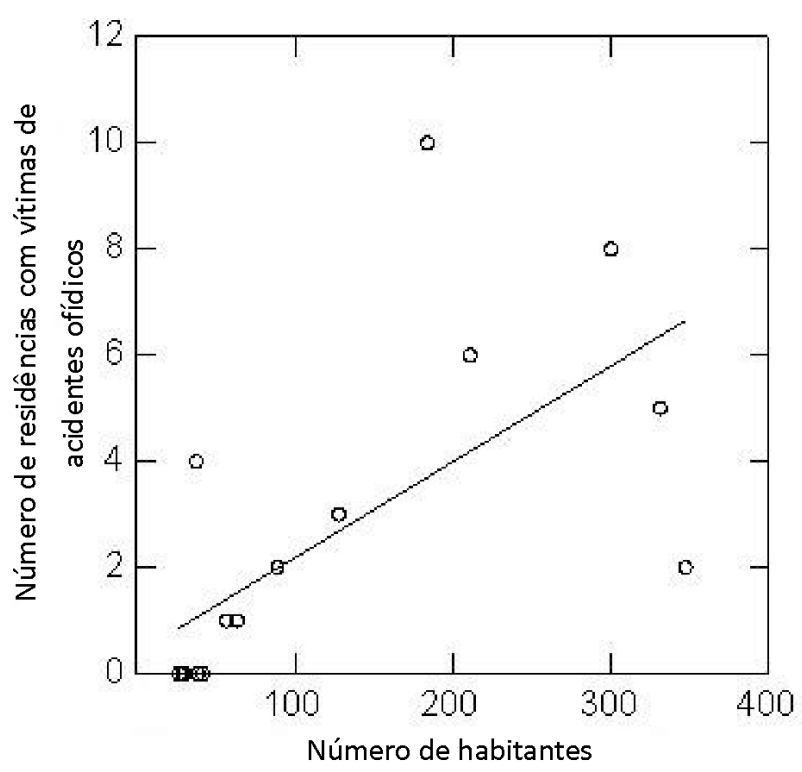

Figura 2 - Relação entre o número de habitantes e o número de residências com vítimas de acidentes ofídicos para 17 comunidades ribeirinhas da Reserva de Desenvolvimento Sustentável Piagaçu-Purus, baixo rio Purus, Amazonas 
Tabela 3 - Freqüência dos acidentes ofídicos no corpo das vítimas de cinco comunidades ribeirinhas no Lago Ayapuá na Reserva de Desenvolvimento Sustentável Piagaçu-Purus, baixo rio Purus, Amazonas.

\begin{tabular}{lcc}
\hline Local da mordida & Número & $\%$ \\
\hline Membros inferiores & 11 & 42,31 \\
\hline Pé & 6 & 23,07 \\
\hline Tornozelo & 4 & 15,38 \\
\hline Panturrilha & 1 & 3,85 \\
\hline Perna & 1 & 3,85 \\
Coxa & & \\
Membros superiores & 2 & 7,69 \\
Mão & 1 & 3,85 \\
Braço & 26 & 100 \\
\hline Total & & \\
\hline
\end{tabular}

média de $219 \mathrm{~mm}(\mathrm{DP}= \pm 310)$, com amplitude que variou de 30 a $1.280 \mathrm{~mm}$.

Em 24 casos também foi possível obter, dos entrevistados, estimativas do tamanho da serpente envolvida no acidente. Foi observado um tamanho médio de $926 \mathrm{~mm}(\mathrm{DP}= \pm 821)$, com amplitude que variou de 200 a $3.840 \mathrm{~mm}$.

Não houve relação significativa entre o tamanho estimado da serpente e a altura da mordida no corpo da vítima $\left(\mathrm{r}^{2}=\right.$ 0,086; $\mathrm{p}=0,165$ ).

A maioria dos acidentes ocorreu durante o dia $(82,14 \%)$, entre 06:00 e 17:00 horas e as seguintes atividades estiveram relacionadas com os eventos: extrativismo florestal $(39,28 \%)$, agricultura $(17,85 \%)$, caça $(17,85 \%)$, atividades na comunidade $(17,85 \%)$ e dentro da água $(7,14 \%)$.

Do total de acidentes registrados ( $\mathrm{N}=28)$, em apenas $25 \%$ dos casos houve administração de soro antiofídico, em média, dentro de 33,14 horas $(\mathrm{DP}= \pm 51,52)$ após o acidente. Em $67,85 \%$ dos casos os vitimados utilizaram outras formas de terapia, como o uso de antibióticos injetáveis, do fitoteráptico “espécífico-pessoa ${ }^{\circledR}$ " e também, de práticas tradicionais que envolveram elementos da fauna e da flora local na fabricação de "antídotos".

Mais da metade $(57,14 \%)$ dos entrevistados relatou ainda sentir complicaçōes de saúde decorrentes dos acidentes. Destes, $31,25 \%$ receberam administração de soro antiofídico.

Foi constatado um único caso de morte por acidente ofídico, de um homem adulto acidentado durante a atividade de coleta de açaí (Euterpe precatoria) na floresta. A serpente relacionada ao acidente foi descrita pelo filho do vitimado como da espécie surucucurana (Bothrops atrox), a espécie mais envolvida nos acidentes registrados na região (Figura 3).

\section{ASPECTOS ECOLÓGICOS}

A maioria dos acidentes $(64,28 \%)$ ocorreu durante o período fluvial de nível mais alto das águas (cheia), entre

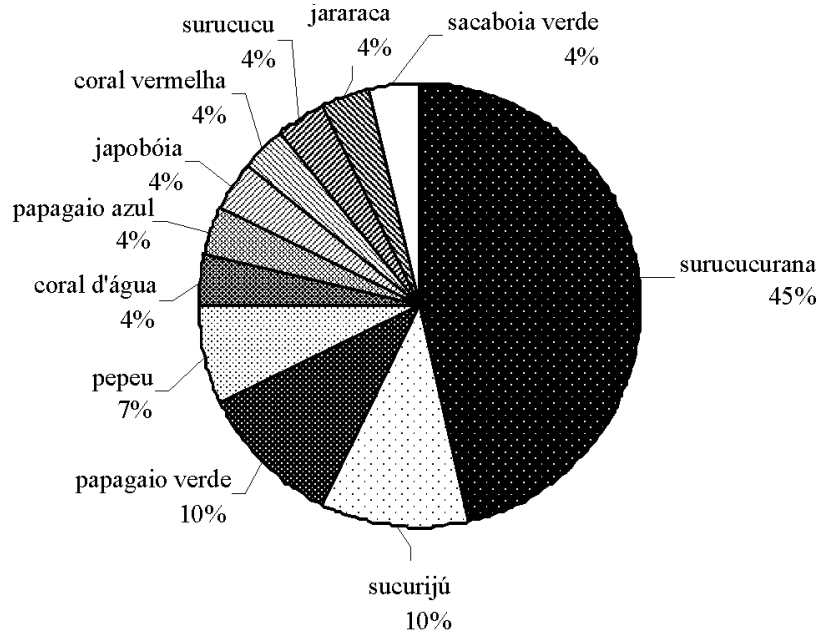

Figura 3 - Proporção das serpentes envolvidas em acidentes ofídicos ( $N=28)$ com ribeirinhos da Reserva de Desenvolvimento Sustentável Piagaçu-Purus, baixo rio Purus, Amazonas. As correspondências entre os nomes locais e científicos das serpentes estão listadas na Tabela 4.

dezembro e junho. Apenas 17,85\% dos acidentes ocorreram durante o período fluvial de menor nível das águas (seca) e uma porcentagem semelhante em período não informado. Mais de $80 \%$ dos acidentes aconteceram no ambiente de terra-firme.

Em 71,43\% dos casos a serpente envolvida no acidente foi morta e em $92,86 \%$ dos acidentes as vítimas alegaram ter reconhecido à espécie de serpente envolvida.

O reconhecimento das espécies pelos ribeirinhos apresentou vários conflitos evidenciados pelas sinonímias, dos 20 nomes locais atribuídos a 33 espécies de serpentes reconhecidas (Tabela 4).

Com relação ao risco de acidentes ofídicos das 33 espécies de serpentes reconhecidas pelos ribeirinhos: $45,5 \%$ foram consideradas agressivas, $33,3 \%$ pacíficas e $21,2 \%$ perigosas (Tabela 4).

Relatos sobre a percepção ambiental dos acidentes com serpentes na região foram obtidos de 13 ribeirinhos, na maioria homens $(84,62 \%)$. Segundo $72 \%$ destes relatos os acidentes ofídicos seriam mais freqüentes no período de cheia, entre dezembro e junho, e sete espécies de serpentes seriam mais envolvidas com os acidentes na região (Figura 4).

As informações obtidas com os ribeirinhos sobre o comportamento de ataque, o horário de atividade e uso dos hábitats das sete espécies de serpente mais envolvidas em acidentes estão resumidas na Tabela 5 . No geral, estas espécies foram reconhecidas como serpentes terrestres e peçonhentas, que ocorrem no chão da floresta, a exceção de três espécies que também possuem hábito arborícola: cobra-papagaio em $80 \%$ das citaçôes, surucucurana em 30,77\% e jararaca em 25\%. 
Tabela 4 - Correspondência entre os nomes científicos e locais de serpentes identificando as sinonímias. 0 risco de acidentes ofídicos para cada espécie esta identificado pelas legendas sobrescritas: $\mathrm{P}=$ perigosa, $\mathrm{A}=$ agressiva e $\mathrm{PC}=$ pacífica.

\begin{tabular}{|c|c|c|}
\hline Nomes locais & Nomes científicos & Sinonímias \\
\hline cobra-de-chuva & $\begin{array}{l}\text { Typhlops reticulatus } \mathrm{s}^{\mathrm{PC}} \\
\text { T. minuisquamus }{ }^{\mathrm{PC}}\end{array}$ & Leptotyphlops sp. ${ }^{\mathrm{PC}}$ \\
\hline cobra-papagaio azul & Oxybelis fulgidus ${ }^{A^{*}}$ & Leptophis ahaetulla ${ }^{\mathrm{A}}$ \\
\hline cobra-papagaio verde ou sacabóia verde & Corallus caninus ${ }^{A}$ & Bothriopsis bilineata ${ }^{\mathrm{P}}$ \\
\hline coral d'água & Micrurus surinamesis ${ }^{P}$ & Hydrops martii ${ }^{\mathrm{A}}$ \\
\hline coral preta & Micrurus hemprichiip & Atractus poeppigipc \\
\hline coral vermelha & Micrurus langsdorffip & Anilius scytale $\mathrm{PC}$ \\
\hline japobóia & juvenis de Bothrops atrox ${ }^{\mathrm{P}}$ & Pseustes poecilonotus ${ }^{\mathrm{A}}$ e Thamnodynastes pallidus ${ }^{\mathrm{A}^{*}}$ \\
\hline jararaca & Leptodeira annulata ${ }^{\mathrm{PC}^{*}}$ & B. atrox $\mathrm{P}^{\mathrm{P}}$ Helicops angulatus ${ }^{\mathrm{A}}$ e Imantodes cenchoa $\mathrm{PC}^{\mathrm{PC}^{*}}$ \\
\hline jibóia branca & Corallus hortulanus ${ }^{A}$ & juvenis de C. caninus ${ }^{A}$ \\
\hline jibóia comum ou verdadeira & Boa constrictor ${ }^{\mathrm{A}}$ & sem sinonímia \\
\hline jibóia vermelha ou salamanta & Epicrates cenchriaA & C. caninus $^{A}$ e C. hortulanus ${ }^{A}$ \\
\hline pepeu & Hydrodynastes gigas ${ }^{A}$ & sem sinonímia \\
\hline sucurijú & Eunectes murinus ${ }^{A}$ & sem sinonímia \\
\hline surradeira & Spilotes pullatus ${ }^{\mathrm{A}}$ & Chironius fuscus ${ }^{A}$ \\
\hline surucucu-pico-de-jaca & Lachesis muta $^{\mathrm{P}}$ & indivíduos maiores da espécie $B$. atrox ${ }^{p}$ \\
\hline surucucurana & B. atrox ${ }^{\mathrm{P}}$ & T. pallidus ${ }^{\mathrm{A}^{*}}$ \\
\hline surucucurana-de-fogo & $\begin{array}{l}\text { Atractus torquatus } s^{\mathrm{PC}}, \text { Drepanoides } \\
\text { anomalus } s^{\mathrm{PC}}, \text { Oxyrhopus formosus } \mathrm{s}^{\mathrm{A}^{*}} \mathrm{e} \\
\text { Oxyrhopus melanogenys } \mathrm{S}^{\mathrm{P}^{*}}\end{array}$ & $\begin{array}{c}\text { Xenopholis scalaris }{ }^{\mathrm{PC}{ }^{\star}} \text { e outras espécies terrestres de } \\
\text { coloração avermelhada }\end{array}$ \\
\hline
\end{tabular}

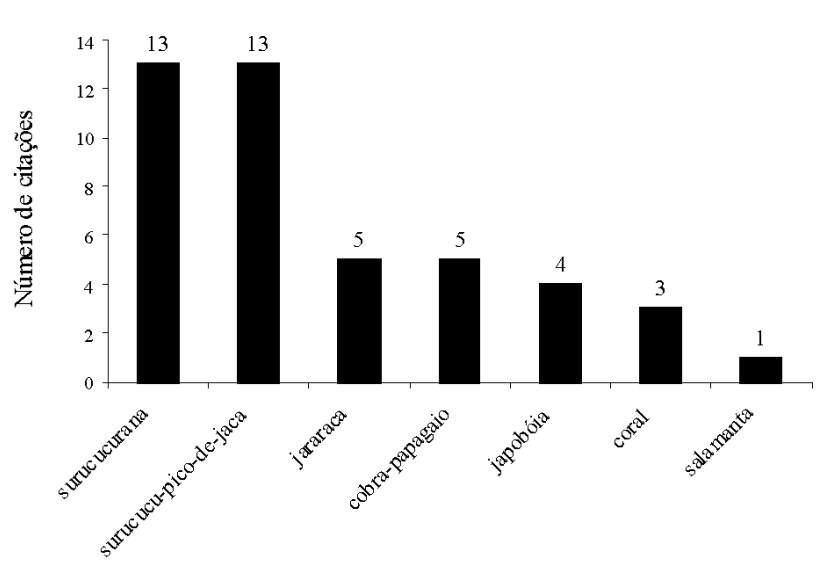

Nomes locais de serpentes

Figura 4 - Serpentes mais freqüentemente envolvidas em acidentes ofídicos citadas por ribeirinhos $(\mathrm{N}=13)$ da Reserva de Desenvolvimento Sustentável Piagaçu-Purus, baixo rio Purus, Amazonas. As correspondências entre os nomes locais e científicos das serpentes estão listadas na Tabela 4.

As espécies surucucurana (Bothrops atrox) e surucucupico-de-jaca (Lachesis muta) foram mencionadas por todos os ribeirinhos entrevistados (Figura 4) e aspectos da ecologia destas espécies foram reportados com maior freqüência (Tabela 5). Estes resultados apontaram que os ribeirinhos reconhecem diferenças no comportamento de ataque das espécies locais mais temidas, com B. atrox descrita como mais agressiva, reagindo com ataque à simples aproximação humana, e
L. muta como menos agressiva, atacando apenas quando molestada ou tocada.

Todos os ribeirinhos vitimados perceberam o evento de acidente como um encontro casual com a serpente, a exceção de um caso no qual o comunitário se sentiu envolvido em uma tentativa de predação por uma serpente sucurijú (Eunectes murinus) de aproximadamente $3,5 \mathrm{~m}$. O evento ocorreu de dia, em uma pescaria solitária de canoa pequena $(4 \mathrm{~m})$, em área de floresta de igapó alagada. O pescador deslocava-se a remo com as pernas na água quando foi surpreendido por uma mordida no pé e afundado sua canoa. $\mathrm{Na}$ água o ribeirinho foi envolvido na cintura pela serpente que lhe constringiu o corpo, tendo quase provocado o afogamento da vítima, que se apoiou na canoa que não afundou completamente, para manter a cabeça fora da água. $\mathrm{O}$ mesmo permaneceu nessa situação por cerca de dez minutos, conseguido se livrar da serpente e subir em uma árvore onde permaneceu até ser socorrido. A vítima ainda relatou, que após o acidente, por cerca de três semanas, apresentou dores e edema e na região da cintura pélvica, e inflamação no local da mordida.

\section{DISCUSSÃO}

Este estudo apresentou um resgate histórico de aproximadamente 50 anos dos acidentes ofídicos para as comunidades avaliadas. A recuperação desta informação, mesmo decorrido um longo período de tempo, foi possível porque em pequenas comunidades amazônicas acidentes com serpentes peçonhentas causam grande mobilização para o 
Tabela 5 - Número de citações sobre a percepção de aspectos ecológicos das serpentes mais envolvidas em acidentes ofídicos de acordo com ribeirinhos da Reserva de Desenvolvimento Sustentável Piagaçu-Purus, baixo rio Purus, Amazonas. As correspondências entre os nomes locais e científicos das serpentes estão listadas na Tabela 4.

\begin{tabular}{|c|c|c|c|c|c|c|}
\hline \multirow{2}{*}{ Espécies } & \multicolumn{2}{|c|}{ Uso dos ambientes } & \multicolumn{2}{|c|}{ Horário de atividade } & \multicolumn{2}{|c|}{ Comportamento de ataque } \\
\hline & terra-firme & áreas alagáveis & diurno & noturno & à aproximação & ao toque \\
\hline cobra-papagaio & 2 & 4 & 4 & 0 & 2 & 2 \\
\hline coral & 4 & 1 & 2 & 2 & 1 & 0 \\
\hline japoboia & 4 & 1 & 3 & 1 & 3 & 1 \\
\hline jararaca & 4 & 3 & 1 & 2 & 3 & 1 \\
\hline surucucu-pico-de-jaca & 12 & 5 & 7 & 6 & 2 & 11 \\
\hline salamanta & 1 & 1 & 1 & 1 & 0 & 1 \\
\hline surucucurana & 11 & 9 & 7 & 10 & 12 & 1 \\
\hline
\end{tabular}

auxílio à vítima, constituído um evento marcante tanto para o vitimado quanto para sua comunidade ficando preservado na memória coletiva.

Um ponto que deve ser considerado em mais detalhes durante este intervalo de tempo amostrado, é a influência sobre os resultados obtidos do êxodo das populaçóes ribeirinhas para os centros urbanos ou comunidades maiores. Relatos de moradores locais apontaram que há 50 anos a população na região do Lago Ayapuá era maior que a atual, devido à maior disponibilidade de recursos naturais e a uma política de incentivo à exploração desses recursos na região, inicialmente da borracha (Hevea spp.) e depois para o comércio de peles animais (ver Marcano et al., 2003).

Esta maior densidade humana poderia resultar em maior freqüência de acidentes, como indicou a análise que envolveu um maior número de comunidades da RDSPP, demonstrando maior probabilidade de ocorrência de acidentes em comunidades maiores (Figura 2). No entanto, nas comunidades onde o presente estudo registrou vítimas, aparentemente outros fatores ambientais e sociais foram mais determinantes para a ocorrência dos acidentes ofídicos que a simples densidade de pessoas.

De fato, vários trabalhos têm sugerido forte relação entre os acidentes ofídicos e os padrōes de atividade humana. Gutiérrez et al. (2006), revisando padrōes globais, relataram variação sazonal na distribuição de acidentes ofídicos relacionada ao clima, especialmente com a estação das chuvas e a temperatura, as mesmas variáveis que determinam os padróes agrícolas anuais.

Trabalhos realizados na Amazônia brasileira (Pardal et al., 1995; Sá-Neto \& Santos, 1995; Dos-Santos et al., 1995; Carvalho \& Nogueira, 1998; Borges et al., 1999; Oliveira \& Martins, 2001) já haviam demonstrado a existência de distribuição sazonal dos acidentes ofídicos para a região, com aumento da incidência ocorrendo no período de maior precipitação. No entanto, talvez em função da variabilidade climática e da subnotificação, esta sazonalidade não é tão marcante em análises territorialmente mais amplas (Ministério da Saúde, 2001).

Alguns dos trabalhos acima mencionados tentaram explicar a distribuição sazonal de acidentes ofídicos por meio da hipótese ecológica de maior adensamento das serpentes durante a cheia, provocada pelo deslocamento dos animais desde as áreas inundáveis (igapós e várzeas) para as áreas não inundáveis de terra-firme (Sá-Neto e Santos, 1995; Dos-Santos et al., 1995). Entretanto, Borges et al. (1999) e Oliveira \& Martins (2001) sugeriram que os padrões de atividade das pessoas e das serpentes poderiam estar relacionados com a intensificação destes eventos durante a época cheia. Os autores chegaram a esta conclusão através da análise de prontuários médicos de 34 municípios do Amazonas (Borges et al., 1999), e do estudo de padrões de atividade de B. atrox e da análise de prontuários de acidentes envolvendo esta espécie no hospital de referência da cidade de Manaus (Oliveira \& Martins, 2001).

Nossos resultados corroboraram esta última hipótese. Nas comunidades pesquisadas foi observada forte relação entre circunstâncias ocupacionais e os eventos de acidentes ofídicos, com o extrativismo florestal sendo a atividade que mais expôs os ribeirinhos aos acidentes. As principais atividades extrativistas da região são a coleta de castanha-da-Amazônia (Bertholletia excelsa) e a retirada de madeira. O pico da extração desses dois recursos ocorre durante o durante o período fluvial de nível mais alto das águas (cheia), pela fenologia de frutificação da castanheira e pelas facilidades de acesso aos locais de extração de madeira e de transporte das toras. Esses fatores aumentam o tempo de atividade dos ribeirinhos em locais com maior risco de acidentes e seriam responsáveis pela maior incidência dos acidentes no período de cheia.

A maior susceptibilidade aos acidentes ofídicos durante o período de cheia, também esteve relacionada com a falta de equipamentos de segurança para realizar as atividades de extrativismo florestal como luvas e calçados apropriados. $\mathrm{O}$ uso de botas com $400 \mathrm{~mm}$ de altura poderia evitar até 84,61\% dos acidentes que tiveram a altura da mordida registrada 
(Figura 5). Estas atividades extrativistas empregam mão-deobra essencialmente masculina o que contribuiu para que os homens tenham sido mais acometidos por acidentes com serpentes nas comunidades estudadas.

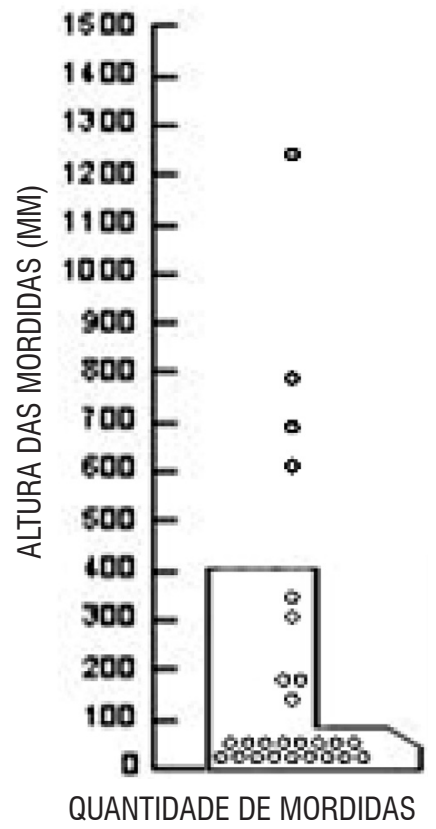

Figura 5 - Altura das mordidas de serpentes $(\mathrm{N}=24)$ no corpo das vítimas com a representação de uma bota com $400 \mathrm{~mm}$ de altura demonstrando sua eficiência para prevenção de acidentes ofídicos em comunidades ribeirinhas da Reserva de Desenvolvimento Sustentável Piagaçu-Purus, baixo rio Purus, Amazonas.

O baixo número de acidentes registrados na comunidade Bom Jesus, localizada em área de várzea (Tabela 1), possivelmente refletiu a maior vocação econômica desta para a atividade da pesca, atividade com baixa exposição dos ribeirinhos a acidentes ofídicos.

Apesar de baixa mortalidade associada aos acidentes com serpentes na região, nas comunidades pesquisadas foi registrada alta morbidade, resultante das seqüelas que dificultam o desempenho das atividades cotidianas por parte dos vitimados (e.g. dificuldade de movimento no membro atingido, perda de tecido no local da mordida, dores recorrentes). Possivelmente, esta morbidade foi decorrente da baixa porcentagem de administração de soro antiofídico às vítimas e, também, ao elevado tempo decorrido entre o acidente e a administração do soro. Nas comunidades estudadas, as vítimas tiveram acesso ao soro antiofídico num tempo médio cerca de seis vezes maior que a média relacionada aos casos de óbito por acidentes ofídicos para outras localidades do Amazonas (ver Borges et al., 1999). Segundo Borges et al. (1999) nestas localidades, em $90 \%$ dos casos letais, as vítimas foram atendidas num tempo superior a seis horas depois do acidente. Os mesmos autores também observaram que o retardo ou a ausência de soroterapia às vítimas foram as principais causas de complicações e letalidade, sendo determinantes da alta taxa de letalidade (1\%) para acidentes ofídicos no estado do Amazonas.

Das serpentes envolvidas nos acidentes registrados, $B$. atrox foi relacionada para aproximadamente metade dos eventos, corroborando outros trabalhos que a colocam como principal serpente de interesse médico da região norte do Brasil (DosSantos et al., 1995; Pardal et al., 1995; Borges et al., 1999) e a maior causadora de acidentes letais na América do Sul (ver Gutiérrez et al., 2006).

Outras três espécies: sucurijú (Eunectes murinus), cobra papagaio verde (Bothriopsis bilineata ou Corallus caninus) e pepeu (Hydrodynastes gigas), representaram 27\% dos acidentes registrados. As duas primeiras espécies já haviam sido reportadas para casos de acidentes ofídicos na Amazônia (Borges et al., 1999). Entretanto, acidentes envolvendo $E$. murinus e $H$. gigas, duas espécies áglifas e semi-aquáticas de grande porte, diferiram do padrão epidemiológico geral. Estes eventos podem ter relação com a atividade de pesca, sendo estas espécies ocasionalmente capturadas por ribeirinhos nas redes de pesca, podendo utilizar a espécie $E$. murinus para extração de gordura com finalidade medicinal (Marioni \& Waldez, no prelo).

O conhecimento das serpentes pelos ribeirinhos se mostrou limitado, com poucos nomes referindo-se de modo inequívoco a uma única espécie, como já observado por Dos-Santos et al. (1995). As seis espécies locais consideradas perigosas, por exemplo, foram reconhecidas por nove nomes locais (Tabela 4), a maioria dos quais apresentaram sinonímias com serpentes consideradas não perigosas. A única exceção foi o nome surucucu-pico-de-jaca, empregado apenas para serpentes efetivamente peçonhentas ( $L$. muta e B. atrox).

Este estudo constatou que apenas quatro dos 19 nomes utilizados pelos ribeirinhos foram inequivocamente empregados para designar uma única espécie: jibóia comum ou verdadeira (Boa constrictor), pepeu (Hydrodynastes gigas) e sucurijú (Eunectes murinus) (Tabela 4).

A maior quantidade de sinonímias foi registrada para $B$. atrox, cuja nomenclatura local refletiu o uso diferencial do hábitat em distintas fases da ontogenia. Juvenis dessa espécie foram reconhecidos pelos ribeirinhos como japobóia, de hábitos arborícolas, distintos daqueles da surucucurana, denominação correspondente aos adultos, de hábitos mais terrestres. Maior frequiência de encontros de juvenis de $B$. atrox na vegetação acima do solo já havia sido observada por Oliveira e Martins (2001), como uma provável adaptação a uma dieta constituída por pequenos anfíbios e lagartos. $\mathrm{O}$ tamanho da serpente também teve influência na denominação popular de $B$. atrox, com indivíduos maiores sendo freqüentemente confundidos com a surucucu-pico-de-jaca (L. muta). 
$\mathrm{Na}$ maioria dos acidentes registrados neste estudo houve a morte da serpente envolvida. $\mathrm{O}$ ato de levar o espécime morto ao posto de saúde poderia ajudar a elucidar grande parte desta profusão de nomes locais, podendo ser útil no tratamento clínico do envenenamento. Para algumas espécies do gênero Bothrops ocorre uma variação ontogenética na composição da peçonha (Kouyoumdjian \& Polizelli, 1989; Ribeiro \& Jorge, 1990; Furtado et al., 1991). Para B. atrox, foram observadas maiores complicações locais e sistêmicas relacionadas ao envenenamento por juvenis desta espécie (Meier, 1986; LópezLozano et al., 2002; Saldarriaga et al., 2003).

A percepção dos ribeirinhos sobre o comportamento de defesa das espécies mais temidas encontrou respaldo em registros da literatura, que descrevem a surucucu-pico-dejaca (L. muta) como de comportamento letárgico durante o dia, permanecendo abrigada e atacando apenas quanto molestada ou tocada (Dos-Santos et al., 1995; Martins \& Oliveira, 1998). Ao contrário, B. atrox pode ser encontrada em atividade durante o dia (Oliveira \& Martins, 2001), o que poderia explicar as circunstâncias observadas na maioria dos acidentes reportados neste estudo, onde $B$. atrox foi a principal espécie causadora e menos de metade das vítimas alegaram ter tocado na serpente.

Circunstâncias acidentais têm sido reportadas como a principal causa de acidentes com animais peçonhentos no Brasil (SINITOX, 2007). Neste estudo, a maioria dos ribeirinhos vitimados reconheceu a casualidade do acidente, por não ter enxergado antecipadamente a serpente, mesmo no período diurno. Estes resultados apontam que, conjuntamente com o aumento da atividade dos ribeirinhos em áreas de floresta, a coloração críptica e o comportamento agressivo de $B$. atrox seriam importantes fatores promotores dos acidentes na região. Borges et al. (1999) relataram predominância de acidentes ofídicos diurnos, para várias localidades do Amazonas. Oliveira \& Martins (2001), entretanto, encontraram maior incidência noturna para acidentes com $B$. atrox, o que pode estar relacionado ao fato do estudo ter sido realizado em Manaus, onde o acesso à energia elétrica pode ter determinado aumento na atividade humana noturna.

Em suma, o levantamento de informação sobre acidentes ofídicos em comunidades ribeirinhas da Amazônia, especialmente nas mais distantes das sedes municipais, pode auxiliar no mapeamento das localidades com altas taxas de subnotificação de acidentes. A identificação de causas ecológicas e epidemiológicas relacionadas aos acidentes ofídicos é essencial para conhecer aspectos particulares aos acidentes da região, a exemplo dos acidentes envolvendo espécies consideradas não-peçonhentas. No Brasil este grupo de serpentes pode representar até $40 \%$ dos casos notificados em centros de referência em ofidismo como o Hospital Vital Brazil, do Instituto Butantan em São Paulo (Salomão et al.,
2003). Adicionalmente, o esclarecimento dos nomes locais das espécies de serpentes pode evitar administrações equivocadas de soro anti-ofídico.

\section{AGRADECIMENTOS}

Aos moradores das comunidades da RDS-PP pela disposição em compartilhar suas experiências de vida. $\mathrm{O}$ Instituto Piagaçu apoiou com a logística em campo e permitiu acesso ao seu banco de dados. A FAPEAM concedeu auxílio PIPT para R.C. Vogt n ${ }^{\circ}$ proc.: 877/2003 e bolsa de doutorado para F. Waldez (POSGRAD 001/2008). O CEUC/SDSAM autorizou a pesquisa na RDS-PP. Hádamo Andrade e Whaldener Endo auxiliaram na aplicação dos questionários. Bruce Bell disponibilizou imagens de satélite da região. Hermógenes Neto confeccionou o mapa da Figura 1. Boris Marioni e Rosélis Mazurek revisaram os textos em Inglês. Dois revisores anônimos acrescentaram valiosas sugestôes à primeira versão deste manuscrito.

\section{BIBLIOGRAFIA CITADA}

Araújo, F.A.A.; Santalúcia, M.; Cabral, R.F. 2003. Epidemiologia dos acidentes por animais peçonhentos. In: Cardoso, J.L.C.; França, F.O.S.; Wen, F.H.; Malaque, C. M.S.; Haddad Junior, V. (Eds). Animais peçonhentos no Brasil: biologia, clinica e terapêutica dos acidentes. Sarvier, São Paulo, SP. p. 6-12.

Barraviera, B.; Pereira, P.C.M. 1994. Acidentes por serpentes do gênero Bothrops. In: Barraviera, B. (Ed). Venenos Animais, uma Visão Integrada. EPUC, Rio de Janeiro, RJ. p. 261-280.

Bartlett, R.D.; Bartlett, P.P. 2003. Reptiles and Amphibians of the Amazon - An Ecoturist's Guide. University Press of Florida, Gainesville. 310pp.

Bernarde, P.S.; Abe, A.S. 2006. A snake community at Espigão do Oeste, Rondônia, southwestern Amazon, Brazil. South American Journal of Herpetology, 1(2): 102-113.

Bochner, R.; Struchiner, C.J. 2003. Epidemiologia dos acidentes ofídicos nos últimos 100 anos no Brasil: uma revisão. Cad. Saúde Pública, 19(1): 7-16.

Borges, C.C.; Sadahiro, M.; Dos-Santos, M.C. 1999. Aspectos epidemiológicos e clínicos dos acidentes ofídicos ocorridos nos municípios do Estado do Amazonas. Rev. Soc. Bras. Med. Trop., 32(6): 637-646.

Campbell, J.A.; Lamar, W.W. 2004. The Venomous Reptiles of the Western Hemisphere. Comstock Publishing Associates, Ithaca and London. 1032pp.

Carvalho, M.A.; Nogueira, F. 1998. Serpentes da área urbana de Cuiabá, Mato Grosso: aspectos ecológicos e acidentes ofídicos associados. Cad. Saúde Pública, 14(4): 753-763.

Chippaux, J.P. 1998. Snake-bites: appraisal of the global situation. Bull. World Health Org., 76(5): 515-524.

Da Silva, R.J., Fecchio, D.; Barraviera, B. 1996. Antitumor Effect of Snake Venoms. J. Venom. Anim. Toxins, 2(2): 79-90. 
Dixon, J.R.; Soini, P. 1986. The reptiles of the upper Amazon basin, Iquitos region, Peru. 2nd ed. Milwaukee Publ. Mus. Milwaukee, Wisconsin. 154pp.

Doan, T.M.; Arizábal A, W. 2002. Microgeographic variation in species composition of the herpetofaunal communities of Tambopata Region, Peru. Biotropica, 34(1): 101-

Dodd, C.K. Jr. 1993. Strategies for Snake Conservation. In: Siegel, R.A.; Collins, J.T. (Eds). Snakes - Ecology and Behavior. McGrawHill, USA, New York. p. 363-393.

Dos-Santos, M.C.; Martins, M.; Boechat, A.L.; Sá-Neto, R.P.; Oliveira, M.E. 1995. Serpentes de interesse médico da Amazônia, Universidade do Amazonas/SESU. Manaus, Amazonas. 64pp.

Duellman, W.E. 1990. Herpetofaunas in Neotropical rainforests: comparative composition, history, and resource use. In: Gentry, A.H. (Ed). Four Neotropical Rainforests. Yale University Press, New Haven, Connecticut. p. 455-505.

Duellman, W.E. 2005. Cusco Amazónico - the lives of amphibians and reptiles in an Amazonian rainforest. Cornell University Press, Ithaca, New York. 433pp.

Fan, H.W.; Cardoso, J.L. 1995. Clinical toxicology of snake bites in South America. In: Meier, J. e White, J. (Eds). Handbook of Clinical Toxicology of Animal Venoms and Poisons. CRC Press, Florida. p. 667-688.

Ferreira, S.H. 1994. University discoveries and intellectual property rights: from Bothrops jararaca bradykinin potentiating peptides to angiotensin converting enzymes inhibitors. Brazilian J. Med. Biol. Res., 27(8): 1693-1698.

Furtado, M.F.D.; Maruyama, M.; Kamiguti, A.S.; Antonio, L.C. 1991. Comparative study of nine Bothrops snakes venom from adult female snakes and their offspring. Toxicon, 29: 219-226.

Furtado. M.F.D. 2007. Aspectos sistemáticos e biológicos que atuam na diversidade da composição de venenos em serpentes peçonhentas brasileiras. In: Nascimento, L.B. \& Oliveira, M.E. (Eds). Herpetologia no Brasil II. Sociedade Brasileira de Herpetologia, Belo Horizonte. p. 183-200.

Greene, H.W. 1997. Snakes: The Evolution of Mystery in Nature. University of California Press, Berkeley and Los Angeles. $351 \mathrm{pp}$.

Gutiérrez, J.M. 1995. Clinical toxicology of snakebite in Central America. In: Meier, J.; White, J. (Eds). Handbook of Clinical Toxicology of Animal Venoms and Poisons. CRC Press, Florida. p. 645-665.

Gutiérrez, J.M.; Sasa, M. 2002. Bites and envenomations by colubrid snakes in Mexico and Central America. J. Toxicol. Toxin Rev., 21 (2002): 105-115.

Gutiérrez, J.M.; Theakston, R.D.G.; Warrell, D.A. 2006. Confronting the neglected problem of snake bite envenoming: The need for a global partnership. PLoS Med., 3(6): 727-731.

Gutiérrez, J.M.; Higashi, H.G.; Wen, F. H.; Burnouf, T. 2007. Strengthening antivenom production in Central and South American public laboratories: report of a workshop. Toxicon, 49(1): 30-35.

Haugaasen, T.; Peres, C.A. 2006. Floristic, edaphic and structural characteristics of flooded and unflooded forests in the lower
Rio Purús region of central Amazonia, Brazil. Acta Amaz., 36(1): 25-36.

Jorge, M.T.; Ribeiro, L.A. 1991. Acidentes causados por animais peçonhentos. In: Amato Neto, V.; Baldy, J.L.S. (Eds). Doenças Transmissiveis. Sarvier, São Paulo. p. 133-141.

Kouyoumdjian, J.A.; Polizelli, C. 1989. Acidentes ofídicos causados por Bothrops moojeni: correlação do quadro clínico com o tamanho da serpente. Rev. Inst. Med. Trop. São Paulo, 31: 8490.

López-Lozano, J.L.; Souza, M.V.; Ricart, C.A.O.; Chávez-Olortegui, C.; Sanchez, E.F.; Muniz, E.G.; Buhrnheim, P.F.; Morhy, L. 2002. Ontogenetic variation of metalloproteinases and plasma coagulant activity in venems of wild Bothrops atrox specimens from Amazonian rain forest. Toxicon, 40: 997-1006.

Marcano, L.C.; Venticinque, E.; Albernaz, A.L.K.M. 2003. Avaliação preliminar da situação sócio-econômica dos moradores do baixo rio Purus. In: Deus, C.P. de; Da Silveira, R.; Py-Daniel, L.H.R. (Eds). Piagaçu-Purus: Bases Cientificas para Criação de uma Reserva de Desenvolvimento Sustentável. Instituto de Desenvolvimento Sustentável Mamirauá, Manaus, Amazonas. p. 13-24.

Marioni, B.; Waldez, F. (no prelo). Natural History Notes. Eunectes murinus (Green Anaconda or Sucuriju). Occasional fishing and Traditional use. Herpetol. Rev.

Martins, M. 1996. Defensive tactics in lizards and snakes: the potential contribution of the Neotropical fauna. In: Del Claro, K. (Ed.). Anais do XIV Encontro Anual de Etologia. Sociedade Brasileira de Etologia, Universidade Federal de Uberlândia, Minas Gerais, Brasil. p. 185-199.

Martins, M; Oliveira, M.E. 1998 (1999). Natural history of snakes in forests of the Manaus Region, central Amazonia, Brazil. Herpetol. Nat. Hist., 6: 78-150.

Meier, J. 1986. Individual and age-dependent variations in the venom of the fer-de-lance (Bothrops atrox). Toxicon, 24: 41-46.

Ministério da Saúde. 2001. Manual de diagnóstico e tratamento de acidentes por animais peçonhentos. Fundação Nacional de Saúde (FUNASA), Brasília, DF. 120pp.

Nascimento, S.P. 2000. Aspectos epidemiológicos dos acidentes ofídicos ocorridos no Estado de Roraima, Brasil, entre 1992 e 1998. Cad. Saúde Pública, 16(1): 271-276.

Oliveira, M.E.; Martins, M. 2001. When and where to find a pitviper: activity patterns and habitat use of the lancehead, Bothrops atrox, in central Amazonia, Brazil. Herpetol. Nat. Hist., 8(2): 101-110.

Pardal, P.P.O.; Monteiro, M.R.C.C; Arnaund, R.N.; Lopes, F.O.B.; Asano, M.E. 1995. Aspectos epidemiológicos de 465 acidentes ofídicos atendidos no HUJBB - Belém - Pará no período de 1993 a 1994. Rev. Soc. Bras. Med. Trop., 28 (supl I): 170.

Pinho, F.M.O.; Pereira, I.D. 2001. Ofidismo. Rev. Assoc. Méd. Bras., 47(1): 24-29.

Praba-Egge, A.D.; Cone, S.W.; Araim, O.; Isabel Freire L.; Paida, G.V.; Escalante, J.T.; Carrera, F.M.; Chavez, M.R.; Merrell, R.C. 2003. Snakebites in the Rainforests of Ecuador. World J. Surg., 27: 234-240. 
Prado-Franceschi, J.; Hyslop, S. 2002. South America colubrid envenomations. Toxin Reviews, 21(1 e 2): 117 - 158.

Puorto, G.; França, F.O.S. 2003. Serpentes não peçonhentas e aspectos clínicos dos acidentes. In: Cardoso, J.L.C.; França, F.O.S.; Wen, F.H; Málaque, Sant'Ana C.M.; Haddad Jr., V. (Eds). Animais Peçonhentos no Brasil. Biologia, clinica e terapêutica dos acidentes. Sarvier, FAPESP, São Paulo. p. 108-114.

Ribeiro, L.A.; Jorge, M.T., 1990. Epidemiologia e quadro clínico dos acidentes por serpentes Bothrops jararaca adultas e filhotes. Rev. Inst. Med. Trop. São Paulo, 32: 436-442.

Roze, J.A. 1996. Coral Snakes of the Americas: Biology, Identification and Venoms. Krieger Publishing Company, Malabar, Florida. $328 \mathrm{pp}$.

Sá-Neto R.P.; Santos M.C. 1995. Aspectos epidemiológicos dos acidentes ofídicos atendidos no Instituto de Medicina Tropical de Manaus (IMTM), 1986-92: estudo retrospectivo. Rev. Soc. Bras. Med. Trop., 28(supl I): 171.

Saldarriaga, M.M.; Otero, R.; Nunez, V.; Toro, M.F. Díaz, A.; Gutiérrez, J.M. 2003. Ontogenetic variability of Bothrops atrox and Bothrops asper snake venoms from Colombia. Toxicon, 42: 405-411.

Salomão, M.G.; Albolea, A.B.P.; Almeida-Santos, S.M. 2003. Colubrid snakebite: a public health problem in Brazil. Herpetol. Rev., 34(3): 307-312.

Serapicos, E.O.; Merusse, J.L.B. 2006. Morfologia e histoquímica das glândulas de Duvernoy e supralabial de seis espécies de colubrídeos opistoglifodontes (Serpentes, Colubridae). Pap. Avuls Zool. 46(15): 187-195.

Savage, J.M. 2002. The Amphibians and Reptiles of Costa Rica: A Herpetofauna between Two Continents, between Two Seas. University of Chicago Press, Chicago. 1934pp.

SBH. 2008. Brazilian reptiles - List of species. (http://www. sbherpetologia.org.br.) Sociedade Brasileira de Herpetologia. Acesso: 14/10/2008.
SINITOX, 2007. Estatística Anual dos Casos de Intoxicação e Envenenamento de 2005. Ministério da Saúde do Brasil, Fundação Osvaldo Cruz (FIOCRUZ), Sistema Nacional de Informações Tóxico-Farmacológicas (SINITOX). Rio de Janeiro, Brasil. (http://www.fiocruz.br/sinitox). Acesso: 15/09/07.

Strüssmann, C.; Sazima, I. 1993. The snake assemblage of the Pantanal at Poconé, western Brazil: faunal composition and ecological summary. Stud. Neot. Faun. Envir., 28: 157-168.

Waldez, F.; Vogt, R.C.; Gordo, M. 2006. Anfíbios e répteis esquamatas da Reserva de Desenvolvimento Sustentável PiagaçuPurus, Amazonas. In: Lopes, J. (Ed). Anais do XXVI Congresso Brasileiro de Zoologia - CD ROM. Sociedade Brasileira de Zoologia. Universidade Estadual de Londrina (EUA), Centro Universitário Filadélfia (UniFil), Londrina, Paraná.

Warrell, D.A. 1992. The global problem of snake bite: Its prevention and treatment. In: Gopalakrishnakone P, Tan, C.K. (Eds). Recent advances in toxinology research. National University of Singapore, Singapore. p. 121-153.

Warrell, D.A. 2003. Injuries, envenoming, poisoning and allergic reactions caused by animals. In: Warrel D.A.; Cox, T.M.; Firth, J.D.; Benz, E.J. (Eds). Oxford Text Book of Medicine. University Press, New York. p. 923-946.

Warrell, D. 2004. Snakebites in Central and South America: epidemiology, clinical features, and clinical management. In: Campbell, J.A.; Lamar, W.W. (Eds). The Venomous Reptiles of the Western Hemisphere. vol. 2. Comstock Publishing Associates, Ithaca and London. p. 709-761.

Wilkinson, L. I990. SYSTAT: The System for Statistics. Evanston, Illinois.

Recebido em 01/10/2007

Aceito em 18/03/2009 